\title{
ESTABLISHING A FRAMEWORK FOR MANAGING INTEREST IN TECHNICAL DEBT
}

\author{
Areti Ampatzoglou, Apostolos Ampatzoglou, Paris Avgeriou \\ Department of Mathematics and Computer Science, University of Groningen, Netherlands \\ areti.ampatzoglou@rug.nl,a.ampatzoglou@rug.nl,paris@cs.rug.nl \\ Alexander Chatzigeorgiou \\ Department of Applied Informatics, University of Macedonia, Thessaloniki, Greece \\ achat@uom.gr
}

Keywords: $\quad$ technical debt $\cdot$ architecture $\cdot$ software quality $\cdot$ interest.

\begin{abstract}
Technical debt (TD) has gained significant attention over the past years. Due to its interdisciplinary nature, it has become attractive for both technical and management stakeholders, to acknowledge and discuss issues related to decayed design-time qualities over time, and their corresponding consequences. Until now, despite the inherent relevance of technical debt management to economics, the TD research community has not sufficiently exploited economical methods/models. Therefore, in this paper we present a framework for managing interest in technical debt, founded on top of well-known economic theories (i.e., Loanable Funds and Liquidity Preference Theory) and current TD research. Specifically, in our framework, we will discuss aspects related to technical debt interest, such as: types of TD interest, TD interest characteristics, and a proposed TD interest theory. Finally, in order to boost the amount of empirical studies in TD research, we will propose several tentative research designs that could be used for exploring the notion of interest in technical debt practice.
\end{abstract}

\section{INTRODUCTION}

The term Technical Debt (TD) was coined in 1992 by Ward Cunningham (1992) to describe the technical compromises being made while coding, in order to speed up product delivery and meet release deadlines. Research on technical debt is rapidly growing over the last years, since around $90 \%$ of articles on the subject have been published after 2010 (Li et al., 2015). Similarly to its success among academics, TD seems to be a topic that is appealing for practitioners, as well. Specifically, according to Li et al. (2015), from the current corpus of research efforts in technical debt, $43 \%$ is performed in academia, $40 \%$ in industry and $17 \%$ in both.

Apart from the fact that TD is a problem of paramount importance for software development, another possible explanation for its popularity, in both academia and industry, is its interdisciplinary nature (software engineering and economics), which facilitates the communication among technical and management stakeholders (Ampatzoglou et al., 2015).
To achieve this, the TD community borrows terms from economics and maps them to software engineering ones. Based on two recent literature reviews on the subject (Ampatzoglou et al., 2015 and $\mathrm{Li}$ et al., 2015), the two most frequently used financial terms in TD research are: interest and principal.

Principal is a clearly defined concept, which is characterized as the effort required to address the difference between the current and the optimal level of design-time quality, in an immature software artefact or the complete software system (Ampatzoglou et al., 2015). Therefore, it is quantifiable and, in general, a commonly accepted concept. On the other hand, interest (associated with many definitions, which in some cases are controversial) cannot be measured in a straightforward way, since it involves the valuation of future maintenance activities. Measuring interest becomes even more complicated due to the fact that its occurrence is not certain, in the sense that extra cost/effort might not be required, and therefore interest will not need to be paid off.

Additionally, research on TD interest and TD in general, appears to lack empirical evidence. Accord- 
ing to $\mathrm{Li}$ et al. (2015) 49\% of the complete corpus of TD research presents no empirical evidence, or only toy examples, whereas this number rises to $56 \%$, when focusing on interest ( $\mathrm{Li}$ et al., 2015).

To partially alleviate these problems, in this study we investigate the notion of interest as it is applied in the TD domain; our goal is to propose FItTeD, i.e., a Framework for managing Interest in Technical Debt. The FItTeD framework, aims to:

(G1) Identify types of TD interest, when it occurs, and the high-level structure of its calculation. Identifying the types of interest, which can occur along evolution, is the first step towards more formal Technical Debt Management (TDM). Until now, the definitions of interest are rather high-level, and interest measurement is often not applied in practice.

(G2) Explore how various characteristics of interest in economics apply in TD interest. An example of such a characteristic is whether interest is simple or compound. However, these characteristics have not been fully exploited in research state-of-the-art, yet.

(G3) Propose a TD interest theory. Until now, no study has used the economic interest theories for modelling technical debt interest. We will rely on the Liquidity Preference Theory, for modelling the evolution of TD.

The cornerstones for the development of FItTeD are:

- The corpus of existing research on Technical Debt Management (TDM). We intend to reuse the primary studies identified in a Systematic Literature Review (SLR) on technical debt by Ampatzoglou et al. (2015), and filter them so as to extract primary studies related to interest, and synthesize them in a systematic way (Kitchenham et al., 2009).

- The existing economic interest theories. We intend to apply existing economic interest theories, i.e., the Loanable Funds and the Liquidity Preference Theory, to reuse existing knowledge from economics, on how interest should be handled, and learn from accumulated experiences.

This framework aims at supporting software engineers to determine the change of technical debt amount in the future, by holistically describing all parameters that affect its future value (i.e., repayment, interest, additional debt, etc.). This can in turn allow the use of elaborate financial methods in several technical debt management activities, i.e., repayment, monitoring, and prioritization. Additionally, we expect that the proposed framework can boost empirical research in the field of $\mathrm{TD}$, in the sense that it can facilitate a common understanding on TD interest and point to interesting research directions.

The rest of the paper is organized as follows: In Section 2, we present related work from the field of economics, i.e., the dominant interest theories. Next, in Section 3, we will present the outcome of revisiting the primary studies of the SLR by Ampatzoglou et al. (2015), by presenting only interest-related information. In Section 4, we present the proposed framework for managing interest in technical debt. In Section 5, we discuss possible ways that our framework can be used for boosting empirical research in the field of TD. Finally, in Sections 6 and 7 , threats to validity and conclusions are presented.

\section{INTEREST IN ECONOMICS}

Regarding the way interest rate is defined in the market; various models have been suggested, by different schools of economics (Mishkin and Eakins, 2012). The mainstream theories are the Loanable Funds Theory, developed by the neoclassical school, and the Liquidity Preference Theory, proposed by the Keynesian theory (Mishkin and Eakins, 2012).

Interest rate is the price paid for borrowing money or vice versa (the payment received to loan money). Therefore it can be considered as the price of money. Interest rate, as any other price, can be defined in the market at the equilibrium between supply and demand. According to the Loanable Funds Theory, interest rate specification takes place in the market of loanable funds. On the one hand, individuals or enterprises, who want to invest, form the demand for loanable funds. They ask for loans in order to proceed with an investment. As interest rate gets higher, borrowing becomes more expensive. As a result, demand for loanable funds decreases as interest rate increases. On the other hand, the supply of loanable funds comes from people or enterprises that use the loanable funds market to save their money. Instead of consuming part of their income, they choose to put it into the loanable funds market in order to save it for later. In this case, higher interest rate means higher return on savings. Therefore, supply of loanable funds rises as interest rate increases.

In the diagram of Figure 1, the equilibrium in loanable funds market is presented. We note that, in economic theory, all kinds of supply - demand diagrams represent the dependent variable on the horizontal axis and the independent variable on the vertical axis. Therefore, in this case, the vertical axis depicts interest rate $(r)$, while the horizontal axis 
represents the quantities of supply and demand for loanable funds. The quantity of loanable funds supplied at any level of interest rate is presented by line $S$. Line S depicts the positive correlation between interest rate and loanable funds supply. Likewise, the quantity of loanable funds demanded at any level of interest rate is presented by line $I$. The negative correlation between interest rate and loanable funds demand is indicated by the negative slope of line I. When interest rate is higher than $r^{*}$, then it is more profitable to save, or it is more profitable to lend than to borrow, and supply of loanable funds is higher than demand. On the other hand, when interest rate $r$ is lower than the level of $\mathrm{r}^{*}$, then it is more profitable to invest, or it is more profitable to borrow than to lend, and demand for loanable funds is higher than supply. When $\mathrm{r}=\mathrm{r}^{*}$, then both the investors and the savers have no motivation to change their position in the market and equilibrium is achieved. Consequently, interest rate is determined at $r=r^{*}$.

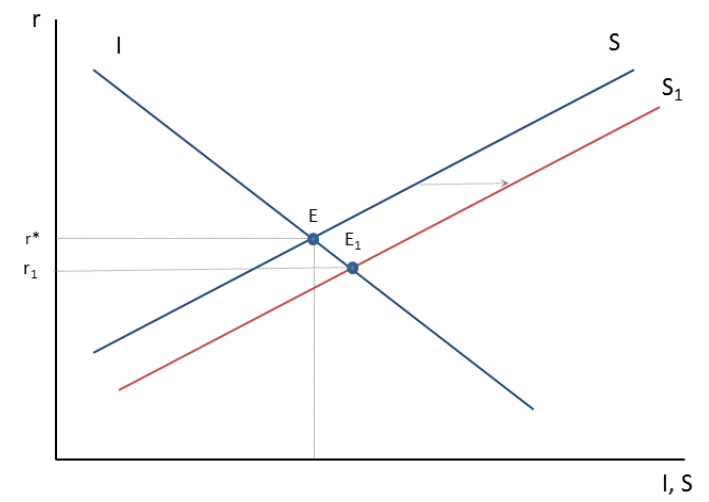

Figure 1: Loanable Funds Theory

Equilibrium in the market is achieved at interest rate $\mathrm{r}^{*}$, when every other factor, that could influence savings or investment, is considered stable (ceteris paribus - i.e., a Latin phrase, often used in economics to suggest that all other factors are constant, in order to examine the relationship between two variables). Therefore, interest rate level may move upwards or downwards in case of changes to savings or investments, due to exogenous factors (e.g., income). For example, an increase in income would cause an increase in the quantity of savings. That would result in a shift to the right of the savings curve (S), which is the supply of loanable funds. In Figure 1, the new line $S_{1}$ depicts such a change. As shown in the diagram, the new equilibrium is now achieved at point $E_{1}$ and interest rate is defined at $r_{1}$, lower than $\mathrm{r}^{*}$.

The Liquidity Preference Theory determines in- terest rate level through the mechanism of supply and demand for money (cash), which is performed in the money market. In this case, supply of money (M) is given at any point of time and is determined by the central bank, according to the needs of the economy. In other words, supply of money is not dependent on interest rate and it is exogenously defined. On the other side, demand for money (L) represents the quantity of cash that people prefer to hold for purposes of transactions, precaution or speculation. In this case, as interest rate increases, it becomes more profitable for people to invest money than to hold it. Consequently, an increase in interest rate leads to a decrease in the quantity of money demanded in the market and a decrease in interest rate causes an increase in demand for money. Similarly to the Loanable Funds theory, interest rate is determined by the equilibrium point of the market.

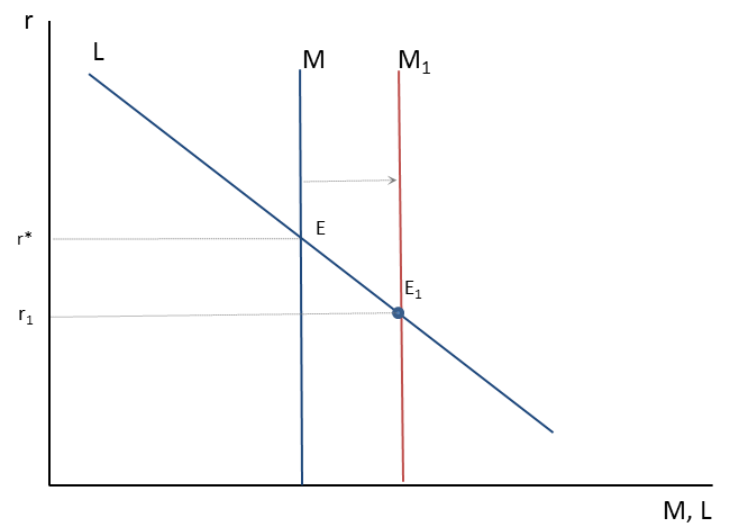

Figure 2: Liquidity Preference Theory

The diagram of Figure 2 shows the equilibrium in the market of money. Interest rate is represented on the vertical axis, whereas money supply and demand are shown on the horizontal axis. The supply curve is vertical to the horizontal axis, and represents the stable money supply, provided by the central bank, independently of the interest rate level, as mentioned above (this assumption consists the main difference with the loanable funds theory). Demand for money is negatively related to interest rate (because in this case interest rate is the cost of holding money against to investing in a bond) and line $L$ shows the quantity of money demanded at any given interest rate, ceteris paribus. The intersection of the two curves, $M$ and $L$, represents market equilibrium and determines the level of the interest rate at $r^{*}$.

In case of a change in demand for money because of a change in another determining factor, e.g. income, or in case of a change in the quantity of money supplied by the central bank, equilibrium rate 
will change. For example, if the central bank decides to increase money supply, then $M$ would increase to $\mathrm{M}_{1}$ and the curve in the diagram of Figure 2 would shift to the right. Consequently, equilibrium would be defined by point $E_{1}$ and the new interest rate in the market would be $r_{1}$, lower than $r^{*}$.

\section{INTEREST IN TECHNICAL DEBT RESEARCH}

In this section we present an overview of studies that have investigated interest in Technical Debt Management (TDM). According to Ampatzoglou et al. (2015) and Li et al. (2015), interest is the prominent financial term that is used in TDM research. Note that in economics, interest theories are used for calculating interest rate (not interest per se), since interest is calculated based on interest rate. However, in TDM interest is not calculated based on interest rate, but it is assessed in various other ways, as explained later in this section. Specifically, from TD research, it is not clear if interest rate can be defined at all. In this study, we reuse the dataset extracted by Ampatzoglou et al. (2015), i.e., 29 studies that focus on $T D$ interest. In this paper, we are not presenting in detail the SLR process, since it is thoroughly discussed in the original study, but only an outline:

- Queried 7 digital libraries (IEEE, ACM, Scopus, Springer, Science Direct, Web of Science, and Google Scholar), with the term technical debt. The search returned 1,173 primary studies

- Applied Inclusion/Exclusion Criteria (e.g., is the study focused on the financial aspect of TD). The process returned 69 primary studies.

From that stage and on, the process is specialized to the goals of this paper. Specifically, first we filtered primary studies related to interest. This step has been performed as part of data collection in the original SLR. Therefore, in this study we explored the 29 primary studies, which according to Ampatzoglou et al. (2015) are relevant to interest. This set of studies is our primary study dataset. For each study, the following data have been extracted:

$\left[\boldsymbol{D}_{1}\right]$ Interest amount definition. We record the definition that the authors provide for the amount of interest. The term interest amount is derived by the work of Seaman and Guo (2011), who suggest that interest should be calculated by taking into account two components interest amount and interest probability (see D2).

$\left[\boldsymbol{D}_{2}\right]$ Interest probability definition. We record how interest probability is defined and calculated.
$\left[\boldsymbol{D}_{3}\right]$ Evolution of Interest. We record any possible discussion that is related to how TD interest amount grows or shrinks, along evolution. For example, we capture if a study characterizes interest as compound or simple, or as continuously increasing.

$\left[\boldsymbol{D}_{4}\right]$ Interest estimation method. We describe how TD interest is quantified in the primary study (when applicable).

The mapping between data extracted and the goals set in Section 1, are discussed below:

G1: We use $\left[\boldsymbol{D}_{1}\right]$ and $\left[\boldsymbol{D}_{2}\right]$. Based on the frequency of each variable, we extract the most common definitions of interest amount and interest probability.

G2: We use $\left[\boldsymbol{D}_{3}\right]$ that is related to studies, which discuss the evolution of technical debt interest. Based on existing literature, and the definitions derived from G1, we formulate the evolution of TD interest, and investigate cases when it is increasing or decreasing.

G3: We use $\left[\boldsymbol{D}_{4}\right]$ that aims at describing how each study assesses the amount of interest or the interest probability, and synthesize them with the financial interest theories and the definitions derived from G1, to develop an interest theory that is applicable for TD.

The outcome of the data collection phase is presented in Table 1 and Table 2. Specifically, in Table 1, we present data $D_{1}$ and $D_{2}$; whereas in Table 2, we present data $D_{3}$ and $D_{4}$. We note that due to space limitations: (a) in both tables, the citation is provided with limited identifiers needed for characterizing a study (e.g., omitting "et al."), and (b) in Table 2, we only present studies that hold a value for at least one variable.

From Table 1, we can observe that about $31 \%$ of primary studies describe interest amount as the extra effort during maintenance, whereas $51 \%$ as the extra maintenance cost. However, since in software economics cost is usually defined as a function of effort, we can assume that $82 \%$ of studies refer to interest amount as the extra effort/cost that is evident during maintenance activities, due to the presence of technical debt. The rest of the studies, either provide more high-level definitions - i.e., (Eisenberg, 2012) and (Letouzey, 2012) - or define technical debt interest, similarly to economics, i.e., the increase rate of technical debt amount (Ernst, 2012), or define interest as a change in a design-time quality attribute - see for example (Seaman et al., 2012) and (Zazworka et al., 2011). Additionally, we can observe that approximately $28 \%$ of the studies acknowledge the existence of interest probability. From these studies, two - i.e., 
(Guo and Seaman, 2012) and (Snipes, 2012) - adopt a financial risk management approach where interest probability is calculated as the standard deviation of interest rate; whereas the rest adopt a risk management approach, i.e., they consider interest probability as the probability of the TD incurring event to occur.

Table 1: Data Extraction Overview. (1/2)

\begin{tabular}{|c|c|c|}
\hline Study & Interest Amount & Interest Probability \\
\hline Allman (2012) & $\begin{array}{l}\text { Increased effort to maintain and extend the } \\
\text { system }\end{array}$ & \\
\hline Alzaghoul (2013) & $\begin{array}{l}\text { Cost incurred by time due to an investment at } \\
\text { service level which is not properly managed }\end{array}$ & \\
\hline Brown (2010) & $\begin{array}{l}\text { Increased future costs owing to earlier quick } \\
\text { and dirty design and implementation choices }\end{array}$ & $\begin{array}{l}\text { The probability that a particular type } \\
\text { of TD will have visible consequences }\end{array}$ \\
\hline Buschman (2011) & $\begin{array}{l}\text { Cost to be paid later due to quick develop- } \\
\text { ment }\end{array}$ & \\
\hline Chin (2010) & $\begin{array}{l}\text { Cost of organization to hold on TD, plus the } \\
\text { additionally incurred debt }\end{array}$ & \\
\hline Codabux (2013) & Additional cost of not eliminating TD now & \\
\hline $\begin{array}{l}\text { Curtis (2012, } \\
\text { Software) }\end{array}$ & $\begin{array}{l}\text { Continuing costs attributable to should-fix } \\
\text { violations that haven't been remediated }\end{array}$ & \\
\hline $\begin{array}{l}\text { Curtis (2012, } \\
\text { MTD) }\end{array}$ & $\begin{array}{l}\text { Continuing costs attributable to should-fix } \\
\text { violations that haven't been remediated }\end{array}$ & \\
\hline Eisenberg (2012) & Long-term impact of TD & \\
\hline Ernst (2012) & The rate of increase in TD & \\
\hline Falessi (2013) & $\begin{array}{l}\text { The cost that will occur by not fixing the } \\
\text { technical problem }\end{array}$ & $\begin{array}{l}\text { Interest is not certain. It has a proba- } \\
\text { bility to occur, changing over time }\end{array}$ \\
\hline de Groot (2012) & $\begin{array}{l}\text { The difference in cost between maintenance } \\
\text { at the ideal level and any level below }\end{array}$ & \\
\hline $\begin{array}{l}\text { Guo and Seaman } \\
\text { (2011) }\end{array}$ & $\begin{array}{l}\text { Extra work that will be needed if TD item is } \\
\text { not repaid }\end{array}$ & $\begin{array}{l}\text { Interest standard deviation, because } \\
\text { of the uncertainty of interest }\end{array}$ \\
\hline Guo et al. (2011) & Additional cost & \\
\hline Holvitie (2013) & $\begin{array}{l}\text { The amount of extra work the principal can } \\
\text { cause to future development }\end{array}$ & $\begin{array}{l}\text { The probability of extra work TD can } \\
\text { cause to future development }\end{array}$ \\
\hline $\begin{array}{l}\text { Koolmanojwong } \\
(2013)\end{array}$ & $\begin{array}{l}\text { More expensive to fix than it is to do it right } \\
\text { the first time }\end{array}$ & \\
\hline Letouzey (2012) & The negative impact of TD & \\
\hline Marinescu (2012) & $\begin{array}{l}\text { Extra maintenance effort required in the fu- } \\
\text { ture due to hasty, inappropriate design }\end{array}$ & \\
\hline McGregor (2012) & $\begin{array}{l}\text { Any extra work over the expected amount, } \\
\text { when later we carry out the deferred activity }\end{array}$ & \\
\hline Nord (2012) & Increasing rework cost of the unpaid TD & \\
\hline Nugroho (2011) & $\begin{array}{l}\text { The extra maintenance cost spent for not } \\
\text { achieving the ideal quality level }\end{array}$ & \\
\hline Schmid (2013) & Additional effort spent on not quite good code & \\
\hline Seaman (2011) & $\begin{array}{l}\text { Potential penalty paid in the future as a result } \\
\text { of not completing tasks in the present }\end{array}$ & $\begin{array}{l}\text { The probability that } \mathrm{TD} \text {, if not repaid, } \\
\text { will make other work more expensive }\end{array}$ \\
\hline Seaman (2012) & Decreasing maintainability & $\begin{array}{l}\text { The probability that TD, if not repaid, } \\
\text { will make other work more expensive }\end{array}$ \\
\hline Siebra (2012) & Extra Effort & \\
\hline Snipes (2012) & $\begin{array}{l}\text { The extra cost required to complete a mainte- } \\
\text { nance activity in the future if the task is post- } \\
\text { poned, plus the cost of other work that is re- } \\
\text { quired due to the presence of the TD }\end{array}$ & $\begin{array}{l}\text { Interest standard deviation, because } \\
\text { of the uncertainty of interest }\end{array}$ \\
\hline
\end{tabular}




\begin{tabular}{|l|l|l|}
\hline \multicolumn{1}{|c|}{ Study } & \multicolumn{1}{c|}{ Interest Amount } & \multicolumn{1}{c|}{ Interest Probability } \\
\hline Zazworka (2011) & Impact on quality & \\
\hline Zazworka (2013) & $\begin{array}{l}\text { An estimate of the amount of extra work that } \\
\text { will be needed if this TD item is not repaid }\end{array}$ & $\begin{array}{l}\text { The probability that TD, if not repaid, } \\
\text { will make other work more expensive }\end{array}$ \\
\hline Zazworka (2014) & Probable future cost of not fixing the TD & \\
\hline
\end{tabular}

Table 2: Data Extraction Overview. (2/2)

\begin{tabular}{|c|c|c|}
\hline Study & $\begin{array}{c}\text { Interest } \\
\text { Evolution }\end{array}$ & Estimation Method \\
\hline Allman (2012) & Compound & - \\
\hline Buschman (2011) & Compound & - \\
\hline Chin (2010) & Both & - \\
\hline Codabux (2013) & Increasing & - \\
\hline Guo and Seaman (2011) & & $\begin{array}{l}\text { Expected interest amount and interest standard deviation can be esti- } \\
\text { mated using historical effort, usage, change, and defect data. }\end{array}$ \\
\hline Guo et al. (2011) & & $\begin{array}{c}\text { Interest }=\text { interest amount } \times \text { interest probability } \\
\text { IA }=\mathrm{X}-\mathrm{P}, \\
\mathrm{X} \text { : Cost of doing something at } \mathrm{t}_{2}\left(\text { after postponing at } \mathrm{t}_{1}\right), \mathrm{P} \text { : principal }\end{array}$ \\
\hline Nord (2012) & Increasing & - \\
\hline Nugroho (2011) & & $\begin{array}{l}\text { interest would be the difference between maintenance effort spent at the } \\
\text { 5-star level and any of the lower quality levels } \\
\qquad \mathrm{ME}=\mathrm{MF} * \mathrm{RV} / \mathrm{QF} \\
\mathrm{MF}=\text { Maintenance Fraction (Historical Data), QF=Quality Factor, } \\
\mathrm{RV}=\text { Rebuild Value (estimate of effort to be spent to rebuild a system) }\end{array}$ \\
\hline Seaman (2011) & & $\begin{array}{l}\text { Interest amount }=\mathrm{W} \times \mathrm{C}, \mathrm{C}=\text { average cost of the last } \mathrm{N} \text { modifications to } \\
\text { module, } \mathrm{W}=\text { weighting factor }, \text { based on the initial rough estimate (high, } \\
\text { medium, or low) of the interest amount }\end{array}$ \\
\hline Siebra (2012) & Increasing & $\begin{array}{l}\text { Estimation based on documentation (chronograms, backlogs and code } \\
\text { lines modifications) as the total effort between alternative scenarios }\end{array}$ \\
\hline
\end{tabular}

Furthermore, the results of Table 2, suggest that approximately $21 \%$ of primary studies deal with the evolution of interest along time and either characterize it as compound, or continuously increasing. As an exception to this, Chin et al. (2010), proposes that one type of interest is simple. Specifically, they suggest that the cost of the organization to hold on TD is stable across time and neither increases nor decreases.

Finally, only $17 \%$ of studies propose a specific way of measuring interest. The estimation is in most of the cases performed by using historical data, documentation, and maintenance effort estimation models (for details see Table 2).

\section{FRAMEWORK FOR MANAGING INTEREST IN TD}

In this section we present FItTeD, i.e., the proposed framework for managing interest in technical debt. While presenting FItTeD, the discussion focuses on goals $\boldsymbol{G 1}-\boldsymbol{G} 3$, as set in Section 1. The proposed framework is based on the findings discussed in Section 3 and on the general perception of interest as the extra effort required for performing any maintenance tasks when technical debt has been accumulated. However, it has been enhanced, by our own suggestions to cover gaps in the current literature.

\subsection{Types of Interest}

From the technical debt literature it is evident that technical debt interest is perceived as a risk for software development, in the sense that it has a specific effect (i.e., interest amount) and a probability to occur (i.e., interest probability). Concerning the amount of interest, we assume that interest can be accumulated through the extra cost incurred by two activities:

- Interest while repaying $T D$ - I(r): The effort for repaying technical debt at any time point $t$ (i.e., enhancing the quality of a Technical Debt Item - TDI) is higher than the effort needed for 
repaying technical debt for this item, at any time point prior to $t$. Therefore, $I(r)$ is calculated as the difference between the two aforementioned efforts. This type of interest will occur when (and if) the amount of TD is to be paid off.

- Interest while performing maintenance activities - $\mathbf{I}(\boldsymbol{m})$ : Performing maintenance tasks is more time/effort consuming in parts of the software with accumulated TD, compared to parts in which TD is reduced or zero. The difference between the two amounts of effort is the amount of the $I(m)$ interest. This type of interest will occur, and will be simultaneously repaid, when maintenance tasks are performed (i.e., while undertaking the effort to perform the maintenance task).

Both the aforementioned types of interest are in agreement with the most established definitions of interest amount (i.e., extra cost/effort); however by adding more details on when these extra costs/efforts can occur. Thus, for each technical debt item, interest $\left(I_{T D I}\right)$ should be calculated, based on the following high-level formula:

$$
\begin{gathered}
I_{T D I}=I(r)+I(m)= \\
=P(r) * E(r)+P(m) * E(m),
\end{gathered}
$$

in which $P$ denotes the probability of a repayment or maintenance event to occur, $E$ the effort needed to perform an action, $r$ denotes repayment, and $m$ other maintenance activities. To transform the aforementioned formula from the TDI level to the systemlevel, we propose the use of the sum aggregation function, in the sense that the total TD of a system is the sum of TD, of all items with incurred TD. Therefore, interest at system level ( $I$ ) can be calculated, as follows:

$$
I=\sum_{j=0}^{j=\text { count }(T D I)} P\left(r_{j}\right) * E\left(r_{j}\right)+P\left(m_{j}\right) * E\left(m_{j}\right)
$$

We note that the aforementioned formulas cannot be used per se, but should be instantiated from researchers, by conducting empirical research that would assign estimates for the $P$ and $E$ factors. For examples and interesting research directions on this issue, see Section 5.

\subsection{Evolution of Interest}

Based on economics, interest is classified over two dimensions: its method of calculation and its variation over time. For these purposes, interest can be:

- Simple or Compound: Interest is simple when it is calculated only as a function of the principal; whereas it is compound when it is calculated over the principal, plus the incurred interest; and

- Fixed or Floating: Interest rate is fixed, if it does not change along time; whereas it is floating when it can increase or decrease based on circumstances.

Technical debt literature has discussed these characteristics of interest, but only superficially, without empirical evidence on the real-world evolution of interest. As already explained in Section 1, interest rate is not defined in technical debt. Therefore, the distinction between floating and fixed interest rates is not applicable. However, interest amount can still increase or decrease, based on the amount of debt that it is calculated upon. To this end, we note that studies which refer to continuously increasing interest are referring to debt amount and not interest amount.

From observing the literature, we can claim that researchers perceive technical debt interest as compound, in the sense that it is increasing, since the additional effort to repay technical debt and perform maintenance on a technical debt item increases as software grows. At any specific point in time $\left(t_{1}\right)$, it is non-trivial to decompose the complexity of the system to the original system complexity $\left(C_{0}\right)$, i.e., the one that existed in the system when the principal incurred, and the additional system complexity $\left(C_{A}\right)$, i.e., the one that incurred due to system evolution (system larger in size, more functionality, etc.). Therefore, the calculation of the effort needed to perform any maintenance action in $t_{1}$, can only be assessed based on system current complexity $\left(C_{C}\right)$.

However, interest is not expected to be continuously increasing. We expect that such a claim only holds for cases when no repayment activities are performed. Specifically, in case that some repayment activity is performed (at $t_{0}$ ), we expect system complexity after partial repayment $\left(C_{R}\right)$ to decrease (i.e., $C_{R}<C_{C}$ ), leading to a decreased amount of both types of interest, in future maintenance activities $E(r \mid m)$. These claims are valid for individual TDIs, in which no additional technical debt has been incurred between timestamps $t_{0}$ and $t_{1}$; and summarized as follows:

$$
\mathrm{I}_{\text {Evolution }}\left\{\begin{array}{l}
E\left(r \mid m_{t 1}\right)>E\left(r \mid m_{t 0}\right), E\left(r_{t 0}\right)=0 \\
E\left(r \mid m_{t 1}\right)>E\left(r \mid m_{t 0}\right), E\left(r_{t 0}\right)<I_{t 0} \\
E\left(r \mid m_{t 1}\right)<E\left(r \mid m_{t 0}\right), E\left(r_{t 0}\right)>I_{t 0}
\end{array}\right.
$$

For example ( $2^{\text {nd }}$ clause): in case the effort spent at time point $t_{0}$ to partially repay technical debt $E\left(r_{t 0}\right)$ is lower than the additional interest incurred at $t_{0}$ 
$I_{t 0}$ then it is reasonable to assume that any future maintenance or repayment effort $E\left(r \mid m_{t 1}\right)$ will be higher than the corresponding effort required at $t_{0}$ $E\left(r \mid m_{t 0}\right)$, in the sense that the amount of debt (diminished design-time quality or complexity) is larger at $t_{0}$ compared to $t_{1}$.

\subsection{Interest Theory}

Based on the above, and by borrowing the rationale of the equilibrium achievement from the existing economic interest theories, we have been able to develop an interest theory for managing TD interest. Specifically, we adopt the concept of the Liquidity Preference Theory. The reason for selecting the Liquidity Preference Theory and not the Loanable Funds Theory is that in TD the amount of money that is available to the company for managing technical debt is stable, i.e., the amount that has been saved, while incurring TD - i.e., the principal (supposing that principal is not invested, to provide extra benefits). The assumption that the available money for managing TD is principal, is based on the fact that principal is the maximum amount that can be spent without spending any additional effort (other than the one saved).

In the proposed interest theory, we map money supply to principal, in the sense that principal is the amount of money that is available to the software development company, after incurring TD; and the money demand to the accumulated amount of interest, in the sense that this is the extra amount of money that is demanded by the company when perform future maintenance activities, caused by the TD. In Figure 3, where we present the FItTeD Interest Theory, the $\boldsymbol{x}$-axis represents time, whereas the $\boldsymbol{y}$-axis represents amount of money. Therefore, the equilibrium point $\left(E_{0}\right)$ denotes the time stamp $\left(t_{0}\right)$, in which the company has spent the complete amount of money from the internal loan (i.e., initial principal $\left.-P_{0}\right)$ in extra maintenance activities because of the incurred TD.

We note that the specification of the equilibrium point is achieved through an analysis based only on effort, i.e., the effort saved when taking on TD and the extra effort required for any future maintenance activity because of its accumulation. Any other related costs or benefits related to technical debt occurrence (e.g. gains from launching the product earlier) have been excluded from the model for simplicity reasons. Thus, if the expected lifespan of the specific TDI is shorter than $t_{0}$ then undertaking technical debt is a beneficial choice, whereas if not, technical debt becomes harmful for the company.
The aforementioned discussions, in the case that no repayment actions are performed, are summarized in the blue lines of Figure 3.

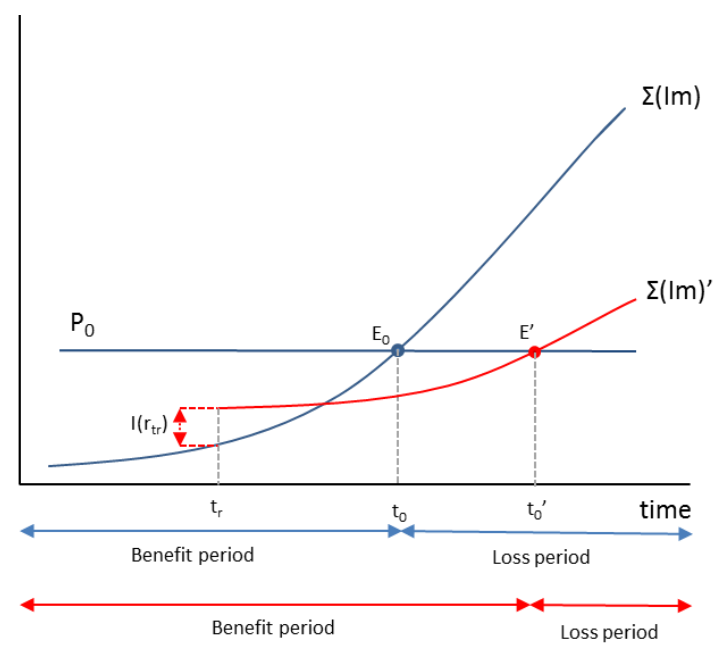

Figure 3: FItTeD Interest Theory

Additionally, in Figure 3, we consider $\Sigma(I m)$ as continuously increasing, since it is a sum of positive numbers and as exponentially increasing, because TD interest is compound (see Section 4.2). In case that some repayment occurs at some timestamp $\left(t_{r}\right)$, the line of the accumulated interest $\Sigma(I m)$ is moved upwards, due to the interest paid for repayment i.e., $I\left(r_{t r}\right)-$ but its slope is decreasing, since the interest is expected to lower for future maintenance activities $(I m)$. This in turn leads to a shift of the equilibrium point $\left(E^{\prime}\right)$ to the right, increasing the benefit period $\left(t_{0}^{\prime}\right)$. The fact that principal is lowered to $P_{t r}\left(P_{t r}<P_{0}\right)$, is not presented in the diagram since the money supply line $\left(P_{0}\right)$ is not moved, because the originally available budget of the company is not affected. The proposed interest theory can help practitioners in their decision making by:

- Identifying the timestamp in which incurring TD, becomes harmful for the company. Thus, they can decide if they should undertake the debt.

- Supporting them on continuously monitoring the interest that they have paid so far.

- Evaluating the repayment activity, based on the time-shift of the equilibrium point that it offers.

\section{RESEARCH IMPLICATIONS}

As already discussed in Section 3 research on TD interest is very theoretical and lacks empirical evidence. Therefore, in this paper we aim at pointing out specific research directions, which would boost 
the empirical research related to TD. The results of these empirical studies would provide data for the instantiation of the FItTeD interest theory. We organize the tentative research design by goal:

Types of Interest: An interesting research direction could be the empirical investigation of:

- whether $I(r)$ and $I(m)$ occur with the same frequency, and

- whether $I(r)$ and $I(m)$ produce a similar amount of interest when they occur,

- how $I(r)$ and $I(m)$ amount could be modelled, as a function of the principal, or the underlying structure of the TDI.

So far, these questions have been explored only by Guo et al. (2011), Nugroho et al. (2011), and Siebra et al. (2012), by exploring historical changes and documentation. The research state-of-the-art lacks real-world evidence on effort allocation.

Evolution of Interest: A possible empirical investigation of the evolution of TD interest could reveal interesting characteristics of TD, such as:

- What is the relationship of the decay of quality in the underlying system structure and the increase in $E(m)$ or $E(r)$ ? Answering this question could guide practitioners on how to model the increase of interest during software evolution.

- How frequently is $E\left(r_{t 0}\right)$ higher or lower than $I\left(r_{t 0}\right)$ ? Answering this question could unveil the frequency with which repayment activities can constitute interest increasing or decreasing.

FItTeD Interest Theory: In order to increase the applicability of the proposed TD interest theory, the following questions need to be empirically explored:

- What is the average time-shift that is benefited from performing specific repayment activities?

- From what factors is this time-shift influenced?

- What is the relationship between $I(r)$ and the average decrease in the $I(m)$ of future maintenance activities?

Answering these questions, would enable practitioners to instantiate the proposed interest theory, based on real and context-specific data, and transform FItTeD into a useful tools for practitioners.

\section{THREATS TO VALIDITY}

In this study, we actually inherit all threats to validity from the original SLR on which we have based our results upon (Ampatzoglou et al., 2015):

- the identification of primary studies

- the generalization of results, and

- the conclusions
Concerning data extraction, since we independently performed this step, the corresponding threats are related only to this study. To mitigate bias, while extracting data, two researchers performed data collection independently, compared the results and discussed possible differences. The final dataset was built through the consent of all authors. Finally, as a threat we acknowledge that the construction of the presented formulas, is to some extent based on the understanding of the authors on TD interest.

\section{CONCLUSIONS}

Nowadays, Technical Debt (TD) is receiving increasing interest by both academia and practitioners, leading to an explosion of studies in this field. The cornerstones of TD are two notions borrowed from economics: i.e., principal and interest. Although principal is a well-established term, interest has so far been discussed in a rather coarse-grained way, with several contradictions among researchers.

In this paper, we propose $F I T T e D$, i.e., a framework for managing interest in TD, which takes into account existing TD literature and economic interest theories. The framework comprise of: (a) a TD interest definition, (b) a classification of TD interest types, (c) a characterization of TD interest evolution, and (d) a TD interest theory, based on the Liquidity Preference Theory. The proposed framework is expected to aid in the decision making of practitioners, and points to interesting research directions. The main emphasis of the future research directions is on empirical studies, which until now are underrepresented in the TD research corpus.

\section{REFERENCES}

Allman E., 2012. Managing technical debt. Communication, 55 (5), pp. 50-55, ACM.

Alzaghoul E., Bahsoon R., 2013. CloudMTD: Using real options to manage technical debt in cloud-based service selection. $4^{\text {th }}$ International Workshop on Managing Technical Debt (MTD '13). IEEE Computer Society.

Ampatzoglou A., Ampatzoglou A., Chatzigeorgiou A., Avgeriou P., 2015. The Financial Aspect of Managing Technical Debt: A Systematic Literature Review. Information and Software Technology, 64, pp. 52-73, Elsevier.

Brown N., Cai Y., Guo Y., Kazman R., Kim M., Kruchten P., Lim E., McCormack A., Nord R., Ozkaya I., Sangwan R., Seaman C., Sullivan K., Zazworka N., 2010. Managing technical debt in software-reliant sys- 
tems. Proceedings of the FSE/SDP workshop on Future of software engineering research, pp. 47 - 52, ACM.

Buschmann F., 2011. To Pay or Not to Pay Technical Debt. Software, 28 (6), pp. 29-31, IEEE Computer Society.

Chin S., Huddleston E., Bodwell W., Gat I., 2010. The Economics of Technical Debt, Cutter IT Journal.

Codabux Z., Williams B., 2013. Managing technical debt: An industrial case study. $4^{\text {th }}$ International Workshop on Managing Technical Debt (MTD '13). IEEE Computer Society.

Cunningham W., 1992. The WyCash Portfolio Management System. $7^{\text {th }}$ International Conference on ObjectOriented Programming, Systems, Languages, and Applications (OOPSLA'92).

Curtis B., Sappidi J., Szynkarski A., 2012. Estimating the Principal of an Application's Technical Debt. Software 29 (6), pp. 34 - 42, IEEE Computer Society.

Curtis B., Sappidi J., Szynkarski A., 2012. Estimating the size cost and types of Technical Debt. $3^{\text {rd }}$ International Workshop on Managing Technical Debt (MTD '12). IEEE Computer Society.

Eisenberg R. J., 2012. A threshold based approach to technical debt. ACM SIGSOFT Software Engineering Notes, 37 (2), pp. 1 - 6, ACM.

Ernst N., 2012. On the role of requirements in understanding and managing technical debt. $3^{\text {rd }}$ International Workshop on Managing Technical Debt (MTD '12). IEEE Computer Society.

Falessi D., Shaw M., Shull F., Mullen K., Keymind M., 2013. Practical considerations challenges and requirements of tool-support for managing technical debt. $4^{\text {th }}$ International Workshop on Managing Technical Debt (MTD '13). IEEE Computer Society.

de Groot J., Nugroho A., Back T., Visser J., 2012. What is the value of your software?, $3^{\text {rd }}$ International Workshop on Managing Technical Debt (MTD '12). IEEE Computer Society.

Guo Y., Seaman C., 2011. A portfolio approach to technical debt management. $2^{\text {nd }}$ International Workshop on Managing Technical Debt. ACM.

Guo Y., Seaman C., Gomes R., Cavalcanti A., Tonin G., da Silva F., Santos A.L., Siebra C., 2011. Tracking technical debt - An exploratory case study. $27^{\text {th }}$ International Conference on Software Maintenance (ICSM '11). IEEE Computer Society.

Holvitie J., Leppanen V., 2013. DebtFlag: Technical debt management with a development environment integrated tool. $4^{\text {th }}$ International Workshop on Managing Technical Debt (MTD '13). IEEE Computer Society.

Kitchenham B., Brereton O. P., Budgen D., Turner M., Bailey J., Linkman S., 2009. Systematic literature reviews in software engineering - A systematic literature review. Information and Software Technology, 51 (1), $p p$ 7-15. Elsevier.

Koolmanojwongand S., Lane J.A., 2013. Enablers and Inhibitors of Expediting Systems Engineering. $11^{\text {th }} \mathrm{An}$ nual Conference on Systems Engineering Research (CSER '13). Procedia Computer Science, Elsevier.
Li Z., Avgeriou P., Liang P., 2015. A systematic mapping study on technical debt and its management. Journal of Systems and Software, 101, pp. 193-220. Elsevier.

Letouzey J. L., 2012. The sqale method for evaluating technical debt. $3^{\text {rd }}$ International Workshop on Managing Technical Debt (MTD '12). IEEE Computer Society.

Marinescu R., 2012. Assessing technical debt by identifying design flaws in software systems. Journal of Research and Development, 56 (5), pp. 1-13, IBM.

McGregor J. D., Monteith J., Zhang J., 2012. Technical debt aggregation in ecosystems. $3^{\text {rd }}$ International Workshop on Managing Technical Debt (MTD '12). IEEE Computer Society.

Mishkin F., Eakins S., 2012. Financial Markets and Institutions. Pearson Prentice Hall, $7^{\text {th }}$ Edition.

Nord R., Ozkaya I., Kruchten P., Gonzalez-Rojas M., 2012. In Search of a Metric for Managing Architectural Technical Debt. 2012 Joint Working IEEE/IFIP Conference on Software Architecture (WICSA) and European Conference on Software Architecture (ECSA). IEEE Computer Society.

Nugroho A., Visser J., Kuipers T., 2011. An empirical model of technical debt and interest. 2nd International Workshop on Managing Technical Debt (MTD' 11). ACM.

Schmid K., 2013. On the limits of the technical debt metaphor some guidance on going beyond. $4^{\text {th }}$ International Workshop on Managing Technical Debt (MTD '13). IEEE Computer Society.

Seaman C., Guo Y., 2011. Measuring and monitoring technical debt. Advances in Computers, 82, pp. 25-46. Elsevier.

Seaman C., Guo Y., Zazworka N., Shull F., Izurieta C., Cai Y., Vetro A., 2012. Using technical debt data in decision making: Potential decision approaches. $3 r d$ International Workshop on Managing Technical Debt (MTD' 12). IEEE Computer Society.

Siebra C. S., Tonin G. S., Silva F. Q., Oliveira R. G., Junior A. L., Miranda R. C., Santos A. L., 2012. Managing technical debt in practice: an industrial report. 6th International Symposium on Empirical Software Engineering and Measurement (ESEM' 12). ACM.

Snipes W., Robinson B., Guo Y., Seaman C., 2012. Defining the decision factors for managing defects: A technical debt perspective. 3rd International Workshop on Managing Technical Debt (MTD' 12). IEEE Computer Society.

Zazworka N., Seaman C., Shull F., 2011. Prioritizing design debt investment opportunities. $2^{\text {nd }}$ International Workshop on Managing Technical Debt (MTD' 11). ACM.

Zazworka N., Spanola R. O., Vetró A., Shull F. Seaman C., 2013. A case study on effectively identifying technical debt. $17^{\text {th }}$ International Conference on Evaluation and Assessment in Software Engineering. ACM.

Zazworka N., Vetró A., Izurieta C., Wong S., Cai Y., Seaman C. Shull F., 2014. Comparing four approaches for technical debt identification. Software Quality Journal. 22 (3), pp. 403 -426, Springer. 